\title{
Capturing migratory birds and examining for ticks (Acari: Ixodida)
}

\author{
Adem KESKININ ${ }^{1,5}$ (D), Kiraz ERCIYAS-YAVUZ ${ }^{2}$ (D), Arif Cemal ÖZSEMİR ${ }^{3}$ (D), Kosta Y. MUMCUOGLU ${ }^{4}$ (i) \\ ${ }^{1}$ Department of Biology, Faculty of Science and Art, Tokat Gaziosmanpaşa University, Tokat, Turkey \\ 2 Ornithology Research Center, Ondokuz Mayıs University, Atakum, Samsun, Turkey \\ ${ }^{3}$ Department of Plant and Animal Production, Bafra Vocational School, Ondokuz Mayıs University, Bafra, Samsun, Turkey \\ ${ }^{4}$ Parasitology Unit, Department of Microbiology and Molecular Genetics, The Kuvin Center for the Study of Infectious and \\ Tropical Diseases, The Hebrew University - Hadassah Medical School, Jerusalem, Israel \\ ${ }^{5}$ Corresponding author: adem.keskin@gop.edu.tr
}

\begin{abstract}
Ticks (Acari: Ixodida) are hematophagous ectoparasites of a wide variety of mammals, birds, reptiles, and amphibians, and are the vectors of many pathogenic agents, such as bacteria, protozoa, and viruses. The seasonal movement and migration of birds is one of the main causes of the dispersal of ticks and tick-borne pathogens. Therefore, identification of ticks associated with migratory birds is a fundamental step to understand the ecology of ticks infesting birds and evaluate their potential as vectors of zoonotic diseases. In this article, we provided a brief review for capturing migrating birds and examining them for ticks.
\end{abstract}

Keywords: Ixodidae, Argasidae, migrating birds, capturing, Turkey.

Zoobank: http://zoobank.org/B85712D5-7FE5-4949-B335-FAF3D89C6A8E

\section{INTRODUCTION}

Wild birds are an important reservoir of several tickborne viral and bacterial agents such as Anaplasma phagocytophilum, Borrelia spp., Coxiella burnetii, Rickettsia spp., and Crimean-Congo hemorrhagic fever virus (Dubska et al., 2009; Ogrzewalska et al., 2009; Elfving et al., 2010; Luz et al., 2012; Keskin et al., 2014; Leblebicioglu et al., 2014; Horak et al., 2018). Migratory birds, play a major role in the transportation of ticks to short or long distances (Hoogstraal et al., 1961; Dietrich et al., 2011; Wallménius et al., 2014), allowing ticks to establish in new areas, though resident birds can also contribute to the dispersion of ticks and tick-borne pathogens (Schneider et al., 2015; Roselli et al., 2020). To understand the eco-epidemiology of various diseases, it is important to study the interactions between ticks, their hosts, pathogens, and their biotic and abiotic environments.

There is a variety of methods to sample free-roaming ticks or ticks from hosts and the choice of a specific method depends on the aim of the surveillance. Ticks can be collected directly from the host animal (alive or hunterkilled, road-killed or dead found), or by dragging/flagging techniques from the vegetation, as well as by examining the nest material of the host animal. In addition, ticks could be collected by $\mathrm{CO}_{2}$ traps and pheromone traps. Selection of incorrect season, location, and timing could end up with inaccurate sampling (Estrada-Peña et al., 2017).

Capturing migratory or resident birds and examining them for ticks is one of the methods to study the ecology of these ectoparasites and the pathogenic microorganisms they might transmit (Hoogstraal et al., 1961; Ralph et al., 2004; Dubska et al., 2009; Elfving et al., 2010;
Keskin and Erciyas-Yavuz, 2019). Long term ringing stations are of paramount importance to study the migration ecology of birds, but also their ectoparasites. In order to study the tick species and their developmental stages found on birds, a collaboration with ornithologists is of utmost importance.

\section{Capturing the birds}

Birds are under protection of the local conservation agencies in many countries of the world, and accordingly ringers should have a legal license and ringing permit. Moreover, in principle legal sellers cannot provide mist nets to people who do not have a license. Ringers are responsible for the safety and welfare of the birds and should conduct their studies under the Ethical Principles in Animal Research and Welfare, which was approved by Animal Ethical Committees.

In order to capture birds, mist nets (Fig. 1), walk-in traps, swim-in traps, funnel traps, clap traps, dip nets, whoosh nets, cannon nets, and nooses are some of the used methods. Mist nets are widely used to catch a high variety of birds within a short period of time and little effort (Dunn and Ralph, 2004a).

Nets should be placed with good trapping probability along a reasonably long control path. It takes some practice to optimize a new location. If the catching area holds active diurnal migration of birds, the mist nets should be placed according to their passage direction. Depending on the catching sites characteristics as wetland, woodland, valley or along a river the mist nets should be placed in front of the optimal feeding vegetation which is expected to increase their capture probability. Nets can be placed in singles or connected in rows. When placed in suitable habitats, these nets are practically invisible for many

\section{DergiPark}



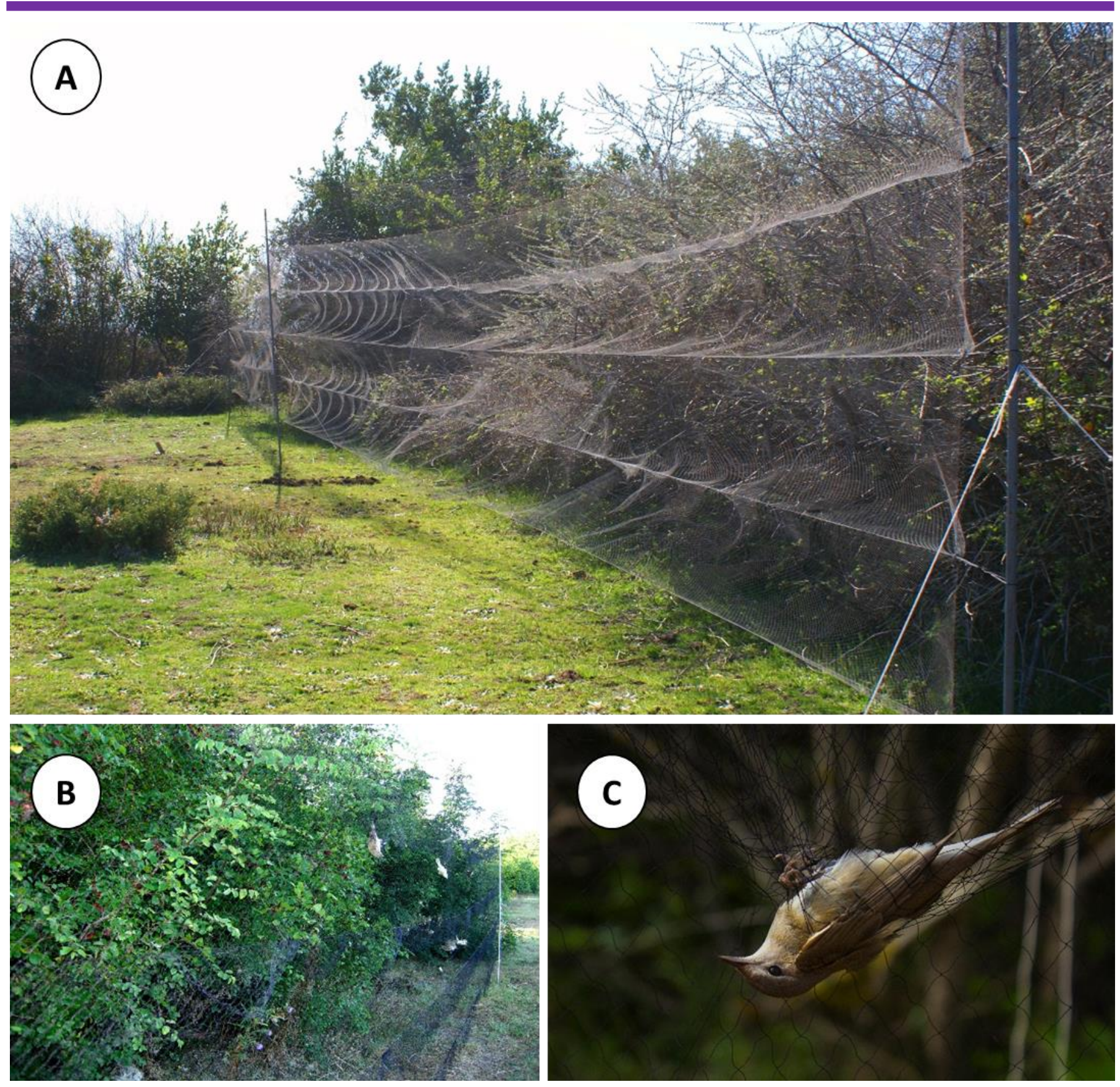

Figure 1. A. Erected mist net in Cernek bird ringing station, B. Caught birds in mist net, C. A Garden Warbler, Sylvia borin, captured by mist net.

birds, resulting with a high capture rate. They are easily transported and can be set up in a variety of habitats. Depending on the species composition, the effective usage of mist nets is related to the habitat selection to erect the mist nets in the study area, and on the correctly selected character of the mist nets (e.g. thinner nets with optimal mesh size, height and length). Mist nets differ in height, length, mesh size, shelve number, thread material and thread thickness. Mist nets have shelves created by horizontally lines that create a flabby and baggy pocket. When a bird hits the net, it falls into this pocket and mainly the wings, head and feet become tangled. The characteristics of the used mist nets will depend on the species composition at the study area, the species-specific sampling target, the habitat of catching, the team (if staff of the station consists of well trained volunteers, easy to extract entangled birds from thinner nets). Small birds can be captured with small mesh size (16-38 $\mathrm{mm})$; whereas larger birds can be captured using large size mesh sizes (45-60 mm). A dho-gaza is a type of mist net that can be used for larger birds, such as raptors.

Required materials for the mist net setting up: Poles (for a standard 2 or 2,5 meter high nets $3-4 \mathrm{~m}$ long): can be produced from cane, bamboo (light, durable, long and suitably robust as mist net poles), wood (often dowel) or metal (preferably aluminum); vegetation chopping equipment; bird-bags, holding bags or paper bags; pegs; and string. Bird bags are used to put extracted birds from mist nets, to transport them safely and to temporarily store them while they are waiting for ringing and investigation. Detailed description of mist netting can be found in the publications of Busse \& Meissner (2015) and Beer et al. (2001). Different sized polyester or nylon mist nets 
can be purchased, e.g., Japanese (Japan), Avinet (USA), and Ecotone (Poland). Having chosen a suitable mist netting site, the mist net is set up as indicated by Gosler (2004), Busse and Meissner (2015) and DBCA (2017).

Major advantages of using mist nets are; (1) low visibility by birds, (2) ease of standardized sampling, (3) relatively free of observer effects due to standardized catching effort, (4) ability to detect species that are often missed using other traps, (5) better statistical analysis of the data by capturing-recapturing birds, (6) opportunity to examine for ectoparasites and diseases of birds, and (7) capture large number of birds with less effort (Dunn and Ralph, 2004; Ralph et al., 2004).

Disadvantages of using mist nets can be; (1) captured birds are at risk of injury or death from predators, (2) exposure to handling or temperature stress, which could be avoided by checking the nets every 30-40 min, (3) learning and avoiding the locations of nets by resident birds. These disadvantages are also distinctive in other catching methods, and the most proper catching method selection will increase the catching performance in relation to the targeted species.

Every captured bird is ringed, which allows to follow up recaptured birds. Bird ringing is an important tool to study birds' ecology, behavior, movements, dispersal, breeding productivity and population change (Baillie et al., 2007; Robinson et al., 2014).

Time and duration of bird capturing and ringing depends on the aim of the study. When targeting migratory birds which are playing an important role in dispersal of ticks and tick-borne diseases, spring and autumn migration seasons are the most appropriate period for passerines, whereas late autumn and early winter would also be important study period for water birds. If resident birds are targeted for the study of ticks and the pathogens they might transmit, the capturing could be done at any time of the year.

Captured birds are transferred within a holding bag to a ringing station, where they are identified, aged and sexed, and then marked with a uniquely coded metal ring (aluminum or steel), and morphometric measurements (such as wing length, tarsus length, and weight) are recorded and thereafter they are released. Re-trapped birds with rings from the same season are checked again only for fat, muscle and weight changes, while re-trapped birds from different years are treated like first capture birds and all measurements are taken again. The ringer rings and takes all the measurements, while a second person, called the writer, notes all dictated data in the bird ringing protocol.

\section{Collection and identification of ticks}

One column at the bird ringing protocol can be generated for the tick recording. While writing the species code, ring code, date, measurements etc., the ringer dictates the writer the number of ticks extracted from examined birds. It is easier to follow up later all the needed information about the bird and ringing details from the bird ringing protocol, than having the ticks' information in a separate form. It is important to record all the birds which have been checked for ticks, including those on which no ticks could be found, in which case a zero should be placed instead of leaving the line blank in the protocol. The number of extracted ticks should be written in the line of the examined species. The writer has to wait until the ringer dictates the total number of extracted ticks, in some birds it is possible to extract several tens of ticks (e.g. a max. of 220 ticks from one Common Blackbird, 163 ticks extracted from one Great Tit, 68 ticks extracted from one European Robin extracted at Cernek Ringing Station).

To ensure minimal stress to the birds, ticks should be collected from birds at a minimum time. Ticks on birds usually attach to base of the beak, ears, eye rims, neck, upper breast and nape (Apanaskevich and Oliver Jr, 2014), however the surrounding of the cloaca, back, belly, and throat of the birds should also be inspected for ticks (Fig. 2). During the examination of the bird, in order to avoid possible escapes from hand, the widely used ringer's grip or the photographer's grip is recommended (De Beer et al., 2001). It was shown that the body part of the tick infestation, may vary among tick species, while some ticks may be found on different parts of the body other than the head (Roselli et al., 2020). If time permits, the bird's whole body should be examined for ticks. If that is not possible, the examined parts must be mentioned in every study. To better visualize the ticks, blowing directly to the feathers and the skin of the bird, could be of help (Fig. 3). A binocular head loupe can be also recommended for collectors of bird ectoparasites. It is especially difficult to detect the un-engorged immatures (larvae and nymphs) in birds with scurf (e.g., Cettia cetti). If a bird is recaptured soon after first capture, it should be checked again for the presence of new ticks or because immatures might have developed to the next stage in the meantime.

Ticks are usually removed with the help of a fine forceps or tick hooks and placed in suitable vials with specific content depending on the study aim. To perform just systematic studies to identify the tick species of a location, site or country the ticks can be transferred alive in vials with a piece of grass to provide humidity. Targeting DNA studies of the tick specimens, the ticks are mostly preserved in $70 \%$ ethyl alcohol, storage at $-20{ }^{\circ} \mathrm{C}$ or freezing at $-70{ }^{\circ} \mathrm{C}$. These specimens can be stored up to two years successfully in ethyl alcohol, which is better than dry storage. Ticks that will be tested for the presence of any pathogenic agents should be placed in absolute ethanol. For RNA virus studies, stabilized buffer (RNAlater) is usually used for storage, where the ticks should be completely submerged in buffer and later stored at $-20{ }^{\circ} \mathrm{C}$ (Estrada-Peña et al., 2017). All vials should be labelled with the name of host species, ring number, and collection date. For birds with long scientific names, standardized ( 5 or 6 alpha codes of bird species) code could be used as abbreviations, e.g. SYATR for Sylvia atricapilla and TUMER for Turdus merula (Busse, 2000; Busse and Meissner, 2015). At Cernek Ringing Station ( $\left.41^{\circ} 36 \mathrm{~N}, 36^{\circ} 05 \mathrm{E}\right)$, the five alpha code is used, where the first two letter indicate the genus, while the last three letters those of the species 


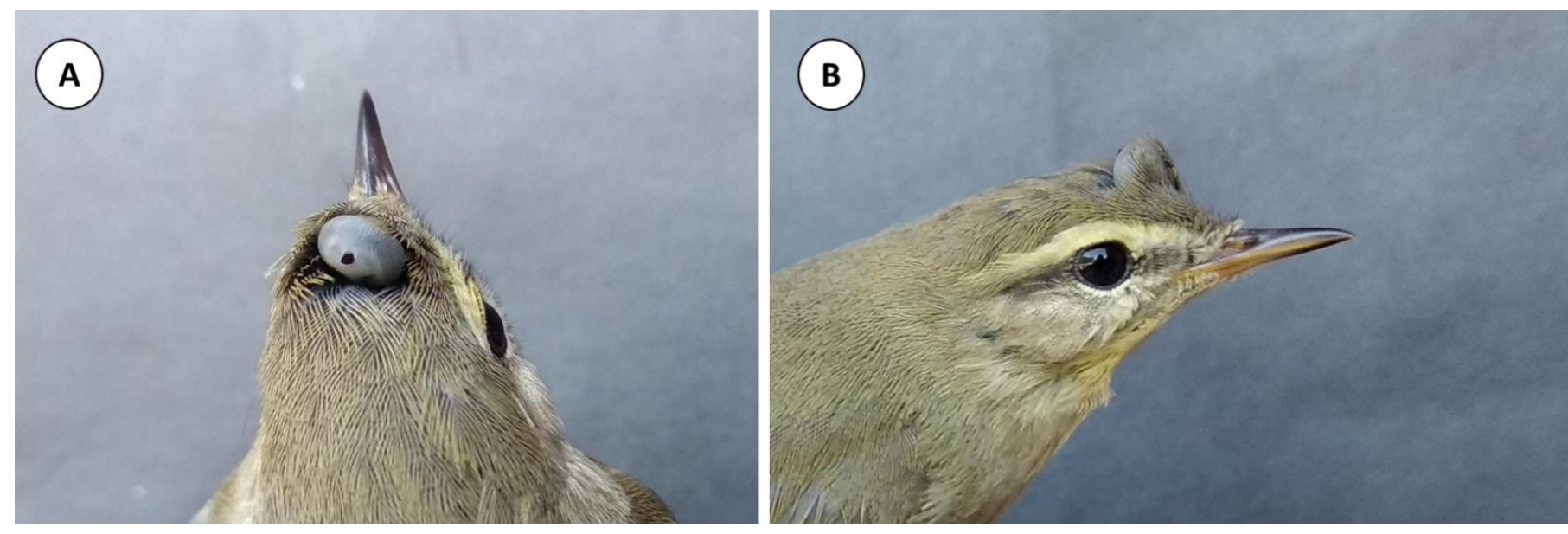

Figure 2. Willow Warbler, Phylloscopus trochilus, parasitized by a fully engorged nymph (Hyalomma sp.). A. Dorsal view, B. Lateral view.

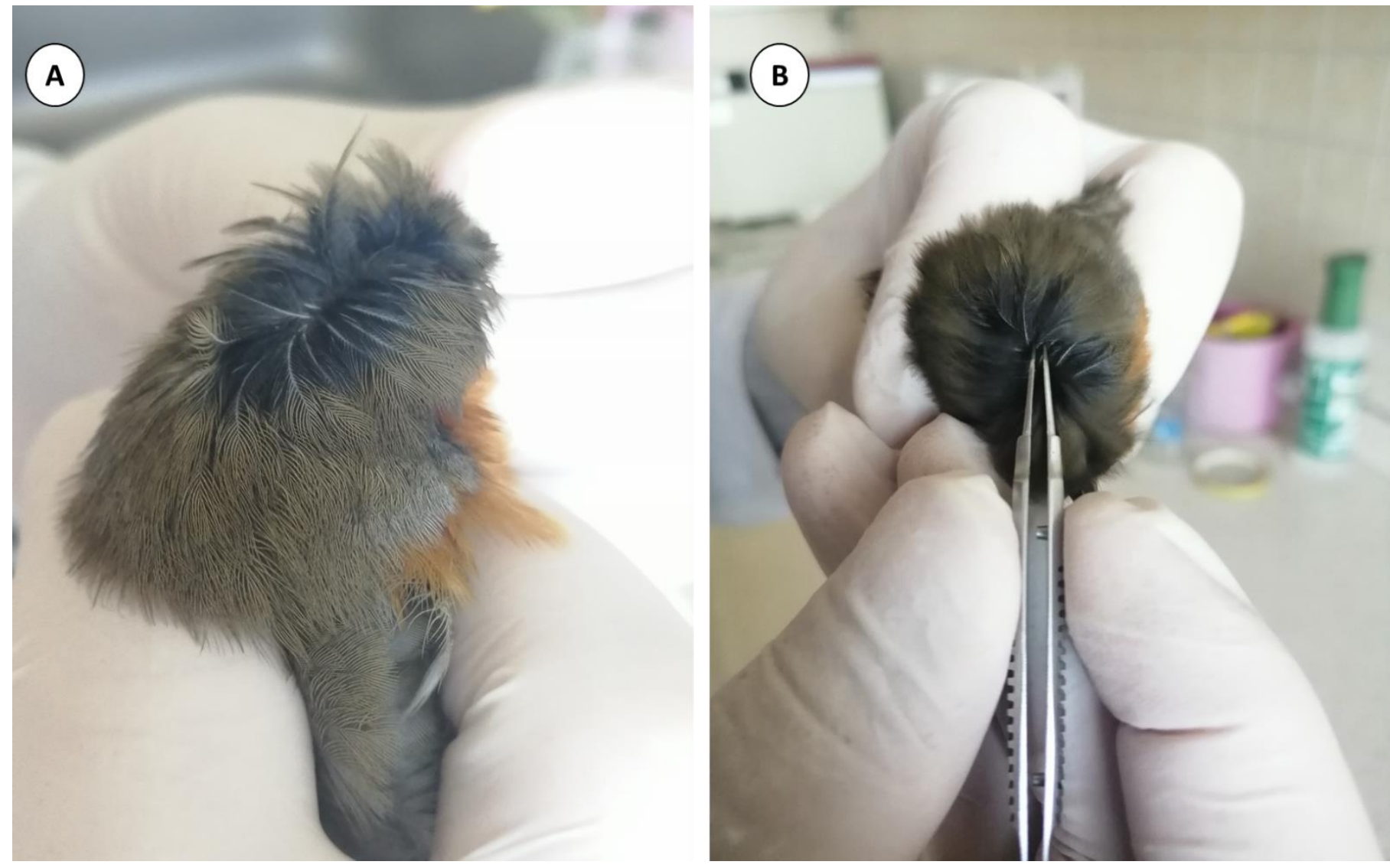

Figure 3. A European Robin, Erithacus rubecula. A. Examination of tick presence, B. Collection of immature ticks by a tweezer.

name. Alternatively, the sampling number recorded on the bird's ringing protocol form can be written on the label. If preferred an individual identical coding system can be used to shorten the process of writing. The ring number or a sampling number can be used which will connect a collected tick to the host species, morphometries of the host species, date of sampling and all other relevant data and information. Depending on the study, ticks collected from one bird can either be stored separately or all in one tube. The decided sampling protocol should be followed, and to avoid any contamination it is recommended to put each tick to separate vials. If there is a need to store the samples at $-20^{\circ} \mathrm{C}$ or $-80^{\circ} \mathrm{C}$ immediately after collection, which is usually not the case in ringing stations which do not have laboratory conditions, it is recommended to use liquid nitrogen tanks to store the samples until they will be transported to the laboratory (Wilkinson et al., 2014; Medlock et al., 2018).

Adult ticks can be easily identified using morphological characteristics, while the identification of immature ticks, especially those of the larvae, can be extremely difficult. The majority of ticks collected from birds are clean and require little or no extra work before placing them under the stereo-microscope. However, in some cases, dirt or host skin secretions can make the identification more difficult. In these cases, ticks should be dipped with a fine brush in alcohol. 

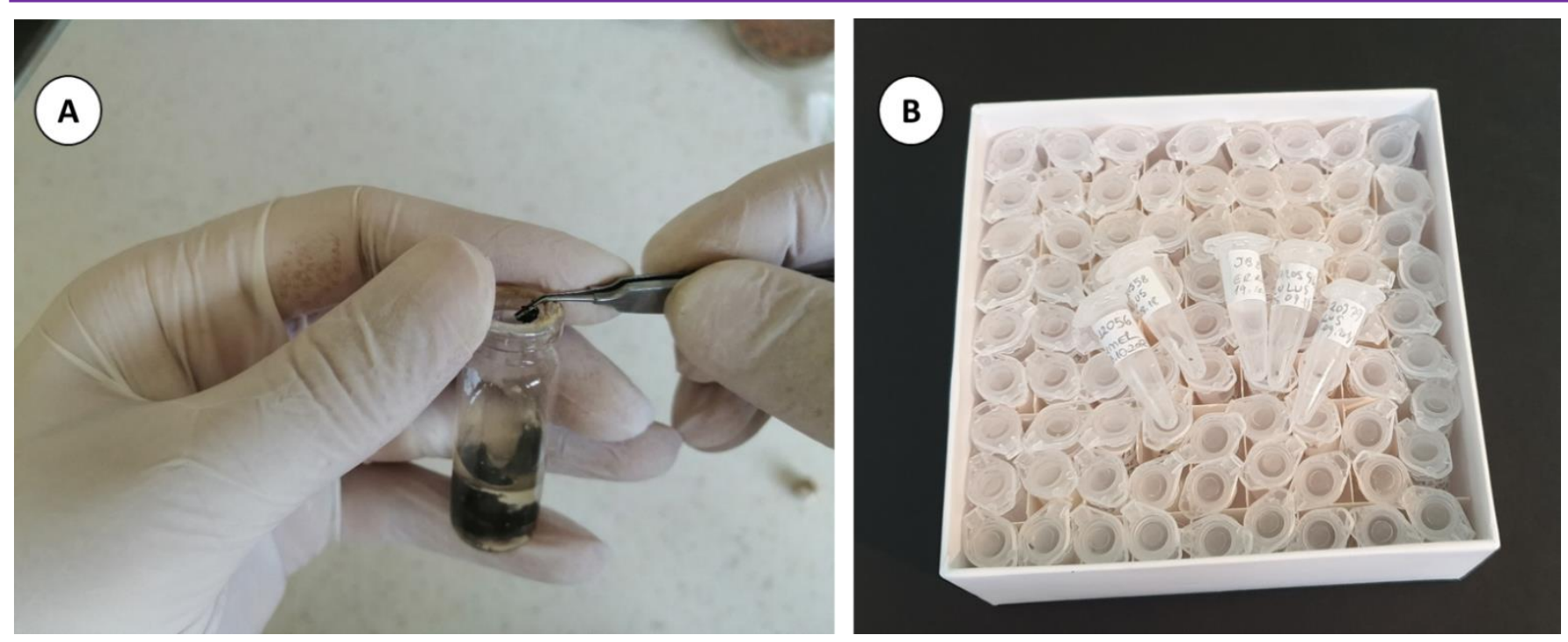

Figure 4. Storing of collected ticks. A. Ticks placed in 70\% ethanol, B. Labelled tubes.

Host skin remains on the hypostome of a tick can be removed using steel tweezers. For the identification of larvae, in many cases, it might be necessary to clear and mount the ticks for their identification under the light microscope. Larval specimens should be cleared with lactic acid at $70^{\circ} \mathrm{C}$ for about 10 minutes. In case those larvae are engorged, they should be punctured and gently squeezed so as to remove much of the blood. Cleared larvae can be mounted in Hoyer's medium (200 g chloralhydrate, $30 \mathrm{~g}$ gum arabic, $20 \mathrm{ml}$ glycerin, $50 \mathrm{ml}$ distilled water). For the clearing and mounting process of larvae, following steps may alternatively be followed; (1)washing in distilled water, (2) clearing in $10 \%$ potassium hydroxide for 1-2 days, (3) washing in distilled water to remove the potassium hydroxide, (4) transferring to lactic acid for at least one hour to make them free from acid, (5) dehydrating in at least 10 minutes in $80 \%, 90 \%$ and absolute alcohol, each, (6) keeping in pure xylene or toluene for ca. 20 minutes, (7) sinking in cloves oil, preferably a day or longer, (8) mounting in Canada Balsam and drying on a hot plate or oven at $80^{\circ} \mathrm{C}$.

Engorged immature ticks could be kept in well ventilated plastic tubes, usually at $25-27{ }^{\circ} \mathrm{C}$ and over $80 \% \mathrm{RH}$, until they molt to the following stage (Allan, 2013).Alternatively molecular tools such as Polymerase Chain Reaction (PCR) can be used for the identification of immature ticks (Black and Piesman, 1994; Karger et al., 2012).

For the collection of endophilic ticks from the bird nests, the nest material should be placed on a mesh over a Berlese-Tullgren funnel. The living immature ticks and also other arthropods within the nest material will move downwards in order to avoid the heat on the top of the examined material and drop into a bottle with $70 \%$ ethanol (Barton, 1995; Mumcuoglu et al., 2005; Kim et al., 2018).

Morphology based identification keys for ixodid and argasid ticks (adults and/or immatures) are available for Palearctic region (Filippova, 1977, 1997; Estrada-Peña et al., 2017); for Nearctic region (Clifford et al., 1961;
Durden and Keirans, 1996); for Neotropical region (Martins et al., 2010; Nava et al., 2017); for Afrotropical region (Arthur, 1965; Horak et al., 2018); for Australian region (Roberts, 1970; Barker and Walker, 2014). For the immature ticks of Rhipicephalus spp. the taxonomic keys of Walker et al. (2000) and for Hyalomma spp. those of Apanaskevich and Horak (2008) could be used.

\section{Conclusions}

Ticks are known vectors of many pathogenic agents of medical and veterinary importance; therefore, they have always attracted the attention of biologists, veterinarians and public health workers. The emergence or reemergence of many pathogenic agents transmitted by ticks infesting birds is also a major global concern, and a collaboration between ornithologists, tick taxonomists, and molecular biologists is of paramount importance. Collaborating with ringing stations gives a good opportunity to widen the scope of tick collection. Also makes the development of monitoring of ticks easier, cheaper and more efficient. Scientists working with ticks could contact local or regional ringing stations in order to add a tick sampling protocol within the ringing procedure without affecting the welfare of birds. Most of the studies do not refer to the infestation rates and focus mainly on the tick-borne diseases. It is recommended to set up a global tick surveillance reporting system to follow the number of examined birds, species of birds, number of ticks, and the ticks found on specific bird species and their density. To quickly relate vector born infections with proper hosts, a public database on tick and their hosts will direct people correctly and increase time efficiency.

\section{Authors' contributions}

Adem Keskin: Conceptualization, methodology, resources, visualization, writing - original draft, writing review \& editing. Kiraz Erciyas-Yavuz: Conceptualization, methodology, resources, visualization, writing - original draft, writing - review \& editing. Arif Cemal Özsemir: Resources, visualization, writing - original draft. Kosta Y. Mumcuoglu: Methodology, supervision, writing - original draft, writing - review \& editing. 


\section{Statement of ethics approval}

Not applicable.

\section{Funding}

There is no fund for the present study.

\section{Conflict of interest}

The authors declare that there is no conflict of interest regarding the publication of this paper.

\section{Acknowledgements}

We would like to thank Dr. Christos Barboutis (Hellenic Ornithological Society/BirdLife Greece, Antikythira Bird Observatory, Athens, Greece) for his valuable comments on the manuscript. We also thank to Gökhan Eren (Faculty of Veterinary Medicine, Ondokuz Mayıs University) for providing the photos to Figures 3 and 4, and to Ömral Ünsal Özkoç (Biology Department, Ondokuz Mayıs University) for providing the picture for the Figure 2.

\section{REFERENCES}

Allan, S.A. 2013. Tick rearing and in vitro feeding.In: Biology of Ticks. Sonenshine, D.E. and Roe, R.M. (Eds), Oxford University Press, New York, NY, USA, 445-473.

Apanaskevich, D.A. and Horak, I.G. 2008. The genus Hyalomma Koch, 1844: V. re-evaluation of the taxonomic rank of taxa comprising the $H$. (Euhyalomma) marginatum Koch complex of species (Acari: Ixodidae) with redescription of all parasitic stages and notes on biology. International Journal of Acarology, 34: 13-42. doi: 10.1080/01647950808683704

Apanaskevich, D.A. and Oliver Jr, J.H. 2014. Life cycles and natural history of ticks. In: Biology of ticks. Sonenshine, D.E. and Roe, R.M. (Eds). Oxford University Press, New York, NY, USA, 59-73.

Arthur, D.R. 1965. Ticks of the genus Ixodes in Africa. The Athlone Press, University of London, London, UK, 348 pp.

Baillie, S., Bairlein, F., Clark, J., du Feu, C., Fiedler, W., Fransson, T., Hegelbach, J., Juillard, R., Karcza, Z., Keller, L.F., Kestenholz, M., Schaub, M. and Spina, F. 2007. Bird ringing for science and Conservation. The European Union for Bird Ringing, Abächerli Druck AG, Sarnen, Switzerland, $33 \mathrm{pp}$.

Barker, S.C. and Walker, A.R. 2014. Ticks of Australia. The species that infest domestic animals and humans. Zootaxa, 3816: 1-144.

doi: 10.11646/zootaxa.3816.1.1

Barton, T.R. 1995. A modified technique for extracting live ticks from small soil and litter samples. Experimental and Applied Acarology, 19: 357-360. doi: $10.1007 /$ BF00052393
Beer, S.J., Lockwood, G.M., Raijmakers, J.M.H., Scott, W.A., Oschadleus, H.D. and Underhill, L.G. 2001. SAFRING Bird Ringing Manual. Animal Demography Unit, Cape Town, 55 pp.

Black, W.C. and Piesman, J. 1994. Phylogeny of hard- and soft-tick taxa (Acari: Ixodida) based on mitochondrial 16S rDNA sequences. Proceedings of the National Academy of Sciences of the United States of America, 91: 10034-10038. doi: 10.1073/pnas.91.21.10034

Busse, P. 2000. Bird Station Manual. Gdańsk: University of Gdańsk Press, Poland, 264 pp.

Busse, P. and Meissner, W. 2015. Bird ringing station manual. De Gruyter Open, Berlin/Munich/Boston, 211 pp.

Clifford, C.M., Anastos, G. and Elbl, A. 1961. The larval Ixodid ticks of the Eastern United States (AcarinaIxodidae). Miscellaneous Publications of the Entomological Society of America, 2: 213-237.

Department of Biodiversity-Conservation and Attractions. 2017. Standard Operating Procedure: Mist Net Trapping for Birds. Perth, WA, USA, $19 \mathrm{pp}$.

Dietrich, M., Gomez-Diaz, E. and McCoy, K.D. 2011. Worldwide distribution and diversity of seabird ticks: implications for the ecology and epidemiology of tickborne pathogens. Vector-Borne and Zoonotic Diseases, 11: 453-470.

doi: $10.1089 /$ vbz.2010.0009

Dubska, L., Literak, I., Kocianova, E., Taragelova, V. and Sychra, 0. 2009. Differential role of passerine birds in distribution of Borreliaspirochetes, based on data from ticks collected from birds during the postbreeding migration period in Central Europe. Applied and Environmental Microbiology, 75: 596-602. doi: 10.1128/AEM.01674-08

Dunn, E.H. and Ralph, C.J. 2004. Use of mist nets as a tool for bird population monitoring. Studies in Avian Biology, 29: 1-6.

Durden, L.A. and Keirans, J.E. 1996. Nymphs of the genus Ixodes (Acari: Ixodidae) of the United States: taxonomy, identification key, distribution, hosts, and medical/veterinary importance. Entomological Society of America, Lanham, Maryland, USA, 95 pp.

Elfving, K., Olsen, B., Bergström, S., Waldenström, J., Lundkvist, A., Sjöstedt, A., Mejlon, H. and Nilsson, K. 2010. Dissemination of spotted fever Rickettsia agents in Europe by migrating birds. PLoS One, 5: e8572. doi: 10.1371/journal.pone.0008572

Estrada-Peña, A., Mihalca, A.D. and Petney, T.N. 2017. Ticks of Europe and North Africa: a guide to species identification. Springer, Cham, Switzerland, 404 pp. 
Filippova, N.A. 1997. Fauna of Russia and neighbouring countries. Ixodid ticks of subfamily Amblyomminae. 4 (5). Nauka Publishing House, St. Petersburg, Russia, $436 \mathrm{pp}$.

Filippova, N.A. 1977. Ixodid ticks (Ixodinae). Fauna USSR New Ser. 4 (4). Nauka, Moscow, Leningrad, Russia, 316 pp.

Gosler, A. 2004. Birds in the hand. In: Bird ecology and conservation: a handbook of techniques. Sutherland, W.J., Newton, I. and Green, R. (Eds). Oxford University Press, New York, NY, USA, 85-118.

Hoogstraal, H., Kaiser, M.N., Traylor, M.A., Gaber, S. and Guindy, E. 1961. Ticks (Ixodoidea) on birds migrating from Africa to Europe and Asia. Bulletin of the World Health Organization, 24: 197-212.

Horak, I.G., Heyne, H., Williams, R., Gallivan, G.J., Spickett, A.M., Bezuidenhout, J.D. and Estrada-Peña, A. 2018. The ixodid ticks (Acari: Ixodidae) of Southern Africa. Springer, Cham, Switzerland, 676 pp.

Karger, A., Kampen, H., Bettin, B., Dautel, H., Ziller, M., Hoffmann, B., Süss, J. and Klaus, C. 2012. Species determination and characterization of developmental stages of ticks by whole-animal matrix-assisted laser desorption/ionization mass spectrometry. Ticks and Tick-borne Diseases, 3: 78-89.

doi: 10.1016/j.ttbdis.2011.11.002

Keskin, A., and Erciyas-Yavuz, K. 2019. Ticks (Acari: Ixodidae) parasitizing passerine birds in turkey with new records and new tick-host associations. Journal of Medical Entomology, 56: 156-161. doi: 10.1093/jme/tjy151

Keskin, A., Koprulu, T.K., Bursali, A., Ozsemir, A.C., ErciyasYavuz, K. and Tekin, S. 2014. First record of Ixodes arboricola (Ixodida: Ixodidae) from Turkey with presence of Candidatus Rickettsia vini (Rickettsiales: Rickettsiaceae). Journal of Medical Entomology, 51: 864867.

doi: 10.1603/ME13169

Kim, H.-C., Park, J.-G., Kwon, Y.-S., Kim, M., Park, C.-U., Yun, S.-M., Chon, S.-T., Kim, M.-S.T., Klein, A. and Robbins, R.G. 2018. Ticks collected from soil/nest litter and live and dead nestlings of migratory seabirds during their breeding season at six uninhabited Islands, Republic of Korea during 2009 and 2014-2017. Systematic and Applied Acarology, 23: 1519-1530.

doi: $10.11158 /$ saa.23.8.3

Leblebicioglu, H., Eroglu, C., Erciyas-Yavuz, K., Hokelek, M., Acici, M. and Yilmaz, H. 2014. Role of migratory birds in spreading Crimean-Congo hemorrhagic fever, Turkey. Emerging Infectious Diseases, 20: 1331-1334. doi: 10.3201/eid2008.131547

Luz, H.R., H. Faccini, J.L., Landulfo, G.A., Berto, B.P. and Ferreira, I. 2012. Bird ticks in an area of the Cerrado of
Minas Gerais State, southeast Brazil. Experimental and Applied Acarology, 58: 89-99.

doi: 10.1007/s10493-012-9572-7

Martins, T.F., Onofrio, V.C., Barros-Battesti, D.M. and Labruna, M.B. 2010. Nymphs of the genus Amblyomma (Acari: Ixodidae) of Brazil: Descriptions, redescriptions, and identification key. Ticks and Tick-borne Diseases, 1: 75-99.

doi: 10.1016/j.ttbdis.2010.03.002

Medlock, J., Balenghien, T., Alten, B., Versteirt, V. and Schaffner, F. 2018. Field sampling methods for mosquitoes, sandflies, biting midges and ticks - VectorNet project 2014-2018. European Centre for Disease Prevention and Control \& European Food Safety Authority. doi: 10.2903/sp.efsa.2018.EN-1435

Mumcuoglu, K.Y., Banet-Noach, C., Malkinson, M., Shalom, U. and Galun, R. 2005. Argasid ticks as possible vectors of West Nile Virus in Israel. Vector-Borne and Zoonotic Diseases, 5: 65-71. doi: $10.1089 /$ vbz.2005.5.65

Nava, S., Venzal, J.M., Acuña, D.G., Martins, T.F. and Guglielmone, A.A. 2017. Ticks of the southern cone of America: diagnosis, distribution, and hosts with taxonomy, ecology and sanitary importance. Academic Press, London, UK, 348 pp.

Ogrzewalska, M., Pacheco, R.C., Uezu, A., Richtzenhain, L.J., Ferreira, F. and Labruna, M.B. 2009. Ticks (Acari: Ixodidae) infesting birds in an Atlantic rain forest region of Brazil. Journal of Medical Entomology, 46: 12251229.

doi: $10.1603 / 033.046 .0534$

Ralph, C. J., Dunn, E.H., Peach, W.J. and Handel, C.M. 2004. Recommendations for the use of mist nets for inventory and monitoring of bird populations. Studies in Avian Biology, 29: 187-196.

Roberts, F.H.S. 1970. Australian ticks. CSIRO, Melbourne, Australia, $267 \mathrm{pp}$.

Robinson, R.A., Morrison, C.A., and Baillie, S.R. 2014. Integrating demographic data: towards a framework for monitoring wildlife populations at large spatial scales. Methods in Ecology and Evolution, 5: 1361-1372. doi: 10.1111/2041-210X.12204

Roselli, M.A., Cady, S.M., Lao, S., Noden, B.H. and Loss, S.R. 2020. Variation in tick load among bird body parts: implications for studying the role of birds in the ecology and epidemiology of tick-borne diseases. Journal of Medical Entomology, 57: 845-851.

doi: $10.1093 /$ jme/tjz228

Schneider, S.C., Parker, C.M., Miller, J.R., Page-Fredericks, L. and Allan, B.F. 2015. Assessing the contribution of songbirds to the movement of ticks and Borrelia burgdorferi in the Midwestern United States during fall migration. Ecohealth, 12: 164-173. doi: 10.1007/s10393-014-0982-3 
Walker, J.B., Keirans, J.E. and Horak, I.G. 2000. The genus Rhipicephalus (Acari: Ixodidae): a guide to the brown ticks of the world. Cambridge University Press, Cambridge, UK, $643 \mathrm{pp}$.

Wallménius, K., Barboutis, C., Fransson, T., Jaenson, T.G., Lindgren, P.-E., Nyström, F., Olsen, B., Salaneck, E. and Nilsson, K. 2014. Spotted fever Rickettsia species in Hyalomma and Ixodes ticks infesting migratory birds in the European Mediterranean area. Parasites and Vectors, 7: 318.

doi: 10.1186/1756-3305-7-318
Wilkinson, D.A., Dietrich, M., Lebarbenchon, C., Jaeger, A., Le Rouzic, C., Bastien, M., Lagadec, E., McCoy, K.D., Pascalis, H., Le Corre, M., Dellagi, K. and Tortosa, P. 2014. Massive infection of seabird ticks with bacterial species related to Coxiella burnetii. Applied and Environmental Microbiology, 80: 3327-3333. doi: 10.1128/AEM.00477-14

Edited by: Salih Doğan

Reviewed by: Three anonymous referees

Citation: Keskin, A., Erciyas-Yavuz, K., Özsemir, A.C. and Mumcuoglu, K.Y. 2021. Capturing migratory birds and examining for ticks (Acari: Ixodida). Acarological Studies, 3 (1): 1-8. 